\title{
Synthesis of glycerophosphorylated cyclic $(1,2)-$ $\beta$-glucans in Rhizobium meliloti strain 1021 after osmotic shock
}

\author{
Michaël W. Breedveld ${ }^{1 *}$ and Karen J. Miller ${ }^{1,2,3}$ \\ Author for correspondence: Karen J. Miller (Department of Food Science). Tel: +1 8148632954. \\ Fax: +18148636132.
}

Department of Food Science', and Graduate Programs in Plant Physiology² and Genetics ${ }^{3}$, The Pennsylvania State University, University Park, PA 16802, USA

\begin{abstract}
The transfer of phosphoglycerol moieties from phosphatidylglycerol to the cyclic (1,2)- $\beta$-glucans in growing cultures of Rhizobium meliloti strain 1021 was investigated using pulse-chase experiments with [ $\left.{ }^{3} \mathrm{H}\right]$ glycerol and/or $\left[{ }^{14} \mathrm{C}\right]$ glucose. No transfer occurred when cells were grown and pulse-chased in a medium containing $0.4 \mathrm{M} \mathrm{NaCl}$. However, radiolabelled glycerophosphorylated cyclic $(1,2)$ - $\beta$-glucans could be detected within $30 \mathrm{~min}$ after transfer of these cultures to a low-osmolarity medium. Conversely, when low-osmolarity cultures were shifted to a high-osmolarity medium containing $0.4 \mathrm{M} \mathrm{NaCl}$ or $0.8 \mathrm{M}$ sucrose, the transfer of phosphoglycerol substituents to the cyclic $(1,2)-\beta$ glucans was inhibited. Further experiments revealed that the transfer of phosphoglycerol substituents to the cyclic $(1,2)-\beta$-glucans occurs within the periplasmic compartment.
\end{abstract}

Keywords: hyperosmotic shock, hypoosmotic shock, glycerophosphate, cyclic $(1,2)-\beta$ glucans, Rbizobium meliloti

\section{INTRODUCTION}

Cyclic $\beta$-glucans are synthesized by all members of the family Rhizobiaceae. In Agrobacterium and Rbizobium species, these molecules contain glucose residues linked solely by $(1,2)-\beta$-glycosidic bonds. Although these glucans are distinguished by their unbranched, cyclic structure, the cyclic $(1,2)-\beta$-glucans of Rhizobium meliloti and Agrobacterium tumefaciens have been shown to share many properties with the linear, branched, membrane-derived oligosaccharides (MDO) of Escherichia coli. These properties include: (i) a (1,2)- $\beta$-linked backbone, (ii) intermediate size (e.g. predominantly 17 to 24 glucose residues for the cyclic $(1,2)-\beta$-glucans and 8 to 10 glucose residues for the MDO), (iii) periplasmic localization, (iv) osmoregulated biosynthesis (with highest levels of synthesis occurring during growth at low osmolarity), and ( $v$ ) the presence of $s n$-1-phosphoglycerol substituents (Breedveld \& Miller, 1994; Kennedy, 1987).

Because the biosynthesis of the cyclic $(1,2)-\beta$-glucans and MDO is osmoregulated, Miller et al. (1986) proposed that both classes of glucans function during hypoosmotic adaptation. Such functions possibly include maintenance of periplasmic volume, reduction in cytoplasmic membrane turgor pressure, maintenance of periplasmic ionic

Abbreviation: MDO, membrane-derived oligosaccharides. and/or osmotic strength, and establishment of a Donnan potential across the outer membrane (Breedveld \& Miller, 1994). Evidence that cyclic (1,2)- $\beta$-glucans do, in fact, function during hypoosmotic adaptation is provided by studies with cyclic $(1,2)-\beta$-glucan-deficient mutants of $A$. tumefaciens and R. meliloti which have been shown to be impaired for growth in hypoosmotic media (Cangelosi $e t$ al., 1990; Dylan et al., 1990). Importantly, the growth of these mutants in hyperosmotic media is indistinguishable from that of wild-type cells (Cangelosi et al., 1990; Dylan et al., 1990). When R. meliloti is grown under hyperosmotic conditions, cyclic $(1,2)-\beta$-glucan synthesis is inhibited, high molecular mass succinoglycan synthesis is stimulated, and compatible solutes are accumulated (by transport and/or synthesis) (Botsford \& Lewis, 1990; Breedveld et al., 1990, 1993; Csonka \& Hanson, 1991; Smith \& Smith, 1989; Zorreguieta et al., 1990).

One critical aspect of the proposed roles for the periplasmic glucans during hypoosmotic adaptation is that these molecules must attain relatively high concentrations within the periplasmic compartment. Indeed, it appears that both MDO and the cyclic $(1,2)-\beta$-glucans are major periplasmic solutes. However, the osmotic potential of these molecules may be greatly enhanced by the presence of charged substituents. Thus, it is particularly intriguing that both classes of periplasmic glucans may become highly substituted with $s n$-1-phosphoglycerol moieties 
derived from the head group of phosphatidylglycerol (Batley et al., 1987; Miller et al., 1986, 1987, 1988; Zevenhuizen et al., 1990). That the presence of these substituents is important is indicated by observations that the majority of phospholipid turnover in R. meliloti and $E$. coli results from the transfer of phosphoglycerol head groups from phosphatidylglycerol to the periplasmic glucans (Schulman \& Kennedy, 1977; Miller et al., 1988). Although two enzymes (phosphoglycerol transferase I and II) have been shown to catalyse the transfer of phosphoglycerol substituents to the MDO of E. coli (Goldberg et al., 1981; Jackson \& Kennedy, 1983; Bohin \& Kennedy, 1984; Jackson et al., 1984), little is known concerning the enzyme(s) responsible for phosphoglycerol transfer to the cyclic $(1,2)-\beta$-glucans of $R$. meliloti

In the present study, we have examined the effects of osmotic up- and downshocks on the synthesis of glycerophosphorylated cyclic $(1,2)-\beta$-glucans in growing cultures of R. meliloti 1021. Our experiments reveal that the phosphoglycerol transferase(s) of $\mathrm{R}$. meliloti is constitutive, yet the rate of phosphoglycerol transfer to the cyclic $(1,2)-\beta$-glucans decreases when cells are subjected to hyperosmotic stress. This is in contrast to the results of previous studies with E. coli showing that phosphoglycerol transferase I retains full activity when cells are grown in media of high osmolarity (Bohin \& Kennedy, 1984).

\section{METHODS}

Bacterial strains and culture conditions. $R$. meliloti strains 1021 and LI1 have been previously described (Breedveld et al., 1994) and were grown in $5 \mathrm{ml}$ standard medium (Breedveld et al., 1990) containing 1 g glutamic acid $\mathrm{l}^{-1}, 5 \mathrm{~g}$ mannitol $\mathrm{l}^{-1}$, mineral salts and vitamins, in the presence or absence of $0.4 \mathrm{M} \mathrm{NaCl}$. Cultures were grown at $30^{\circ} \mathrm{C}$ on a rotary shaker.

Pulse-chase experiments. Cells from mid-exponential phase $\left(\mathrm{OD}_{650} \quad 0 \cdot 4-0 \cdot 6\right)$ were pulse-labelled with $\left[2-{ }^{3} \mathrm{H}\right]$ glycerol $\left(50 \mu \mathrm{M}, 12000\right.$ c.p.m. nmol $\left.{ }^{-1}\right)$ or $\left[\mathrm{U}_{-}{ }^{14} \mathrm{C}\right]$ glucose $(100 \mu \mathrm{M}$, 5000 c.p.m. nmol $^{-1}$ ) for 15 or 30 min. After centrifugation and two washes with culture medium lacking radioactive substrate, cells were chased in medium containing $50 \mu \mathrm{M}$ glycerol or $100 \mu \mathrm{M}$ glucose in the presence or absence of $\mathrm{NaCl}$ as indicated. In some experiments, chloramphenicol $\left(100 \mu \mathrm{g} \mathrm{ml}^{-1}\right)$ was added to cultures at the beginning of the chase period. At various times during the chase period, cultures were centrifuged, and radiolabelled cyclic $(1,2)-\beta$-glucans were extracted from cell pellets into aqueous methanol (Miller et al., 1988). Radiolabelled cyclic glucans were analysed by gel permeation and ion-exchange column chromatography as previously described (Breedveld $e t$ al., 1994). Extracellular cyclic $(1,2)-\beta$-glucans were not analysed because more than $97 \%$ of the total radiolabelled cyclic glucan pool was found to be associated with the cell pellet during the chase period, in both the presence and absence of $\mathrm{NaCl}$.

Cellular localization of the radiolabelled cyclic $(1,2)-\beta$ glucans. Cells were grown in standard medium containing no added $\mathrm{NaCl}$. After reaching an $\mathrm{OD}_{650}$ of approximately 0.5 , cultures were pulse-labelled with $\left[{ }^{14} \mathrm{C}\right]$ glucose for $15 \mathrm{~min}$ as described above. After washing with unlabelled growth medium, the cellular location of the radiolabelled cyclic $(1,2)-\beta$ glucans was examined using polymyxin $B$ as described by Hirst \& Holmgren (1987). These researchers have previously reported that treatment with polymyxin B results in the selective extraction of periplasmic proteins from Vibrio cholerae. Briefly, washed cell pellets (derived from an original culture volume of $1 \mathrm{ml}$ ) were resuspended in $1 \mathrm{ml}$ ice-cold $0.9 \%(\mathrm{w} / \mathrm{v}) \mathrm{NaCl}$ containing $2000 \mathrm{U}$ polymyxin $\mathrm{B}$. The suspension was incubated at $4{ }^{\circ} \mathrm{C}$ for $15 \mathrm{~min}$, then centrifuged $(5000 \mathrm{~g})$, and the supernatant examined for the presence of radiolabelled cyclic $(1,2)-\beta$ glucans by gel permeation and ion-exchange chromatography.

Chemicals. $\left[2-{ }^{3} \mathrm{H}\right]$ Glycerol was obtained from ICN Radiochemicals, and $\left[\mathrm{U}_{-}{ }^{14} \mathrm{C}\right]$ glucose from New England Nuclear. Polymyxin B sulfate was obtained from Sigma. All other chemicals were of analytical grade.

\section{RESULTS}

\section{Synthesis of glycerophosphorylated cyclic $(1,2)-\beta$ - glucans is inhibited upon osmotic upshift}

When R. meliloti 1021 cells were pulse-labelled with [2${ }^{3} \mathrm{H}$ ]glycerol and chased in standard medium, a continuous increase in radiolabel was detected within aqueous methanol extracts during the chase period (Fig. 1). Further analysis by gel permeation and ion-exchange chromatography revealed that anionic ${ }^{3} \mathrm{H}$-labelled cyclic $(1,2)-\beta$ glucans represented $\geqslant 93 \%$ of the radiolabel present within these extracts. In a previous study, similar results were reported, and it was shown that $\left[{ }^{3} \mathrm{H}\right]$ phosphoglycerol (derived from the head group of phosphatidylglycerol) accounted for all of the radiolabel associated with the ${ }^{3} \mathrm{H}$-labelled cyclic $(1,2)-\beta$-glucan fraction (Miller et al., 1988).

When cultures were subjected to a hyperosmotic shift at the start of the chase period, the biosynthesis of

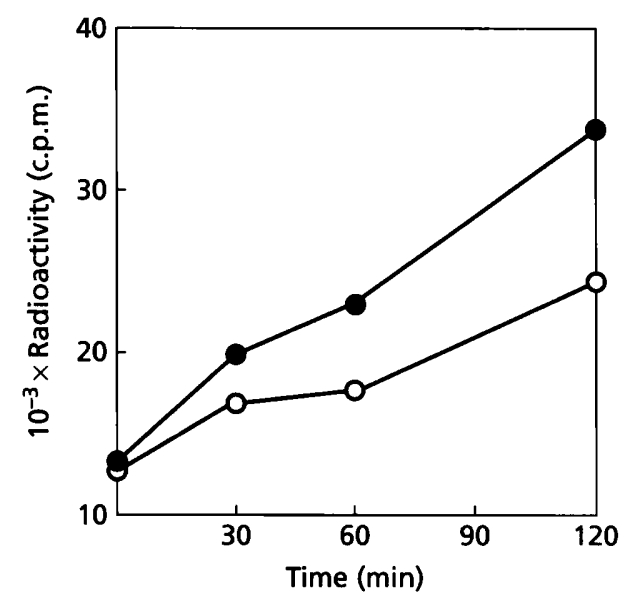

Fig. 1. Pulse-chase experiment with $\left[2-{ }^{3} \mathrm{H}\right]$ glycerol. Cells of $R$. meliloti 1021 were pulse-labelled for $30 \mathrm{~min}$ with $\left[2-{ }^{3} \mathrm{H}\right] \mathrm{glycerol}$ in standard medium containing no added $\mathrm{NaCl}$. Chase conditions (beginning at time 0 ) were performed in the presence $(O)$ or absence $(O)$ of $0.4 \mathrm{M} \mathrm{NaCl}$ as indicated. The results are expressed as total c.p.m. per $5 \mathrm{ml}$ culture and represent the appearance of $\left[{ }^{3} \mathrm{H}\right]$ glycerophosphorylated cyclic $(1,2)$ - $\beta$-glucans within aqueous methanol extracts during a $120 \mathrm{~min}$ chase period. $\left[{ }^{3} \mathrm{H}\right]$ Glycerophosphorylated cyclic $\beta$ glucans were identified by gel permeation chromatography on Sephadex G50 (not shown). Radiolabel in the non-glucan fraction (less than $7 \%$ of the total radiolabel within aqueous methanol extracts) has been subtracted in both cases. 

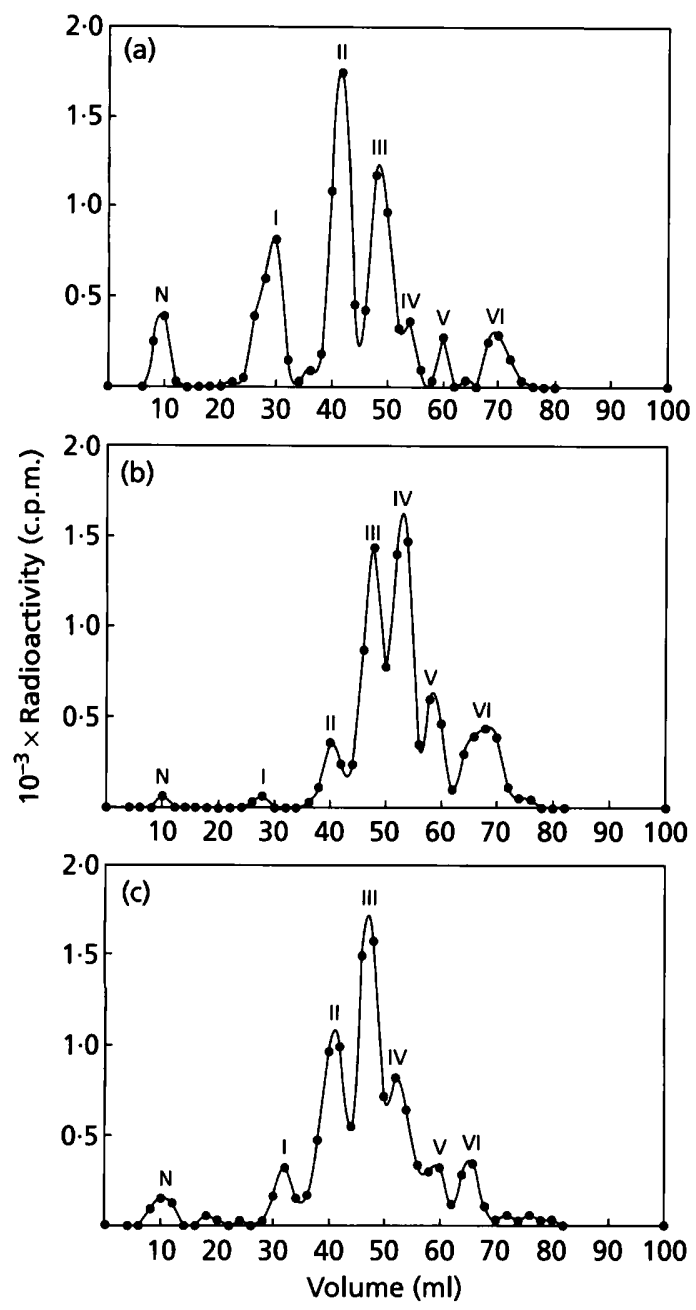

Fig. 2. DEAE-cellulose chromatography profiles of ${ }^{14} \mathrm{C}$-labelled cyclic $(1,2)-\beta$-glucans of $R$. meliloti 1021 during chase conditions in the absence and presence of $0.4 \mathrm{M} \mathrm{NaCl}$. A $5 \mathrm{ml}$ culture was labelled with $\left[{ }^{14} \mathrm{C}\right]$ glucose for $15 \mathrm{~min}$ in standard medium containing no added $\mathrm{NaCl}$. After washing, cells were subjected to chase conditions for $4 \mathrm{~h}$ in standard medium containing either no added $\mathrm{NaCl}$ or $0.4 \mathrm{M} \mathrm{NaCl}$. Cells were extracted with aqueous methanol, and extracts were chromatographed on Sephadex G50. Radiolabelled cyclic $(1,2)$ - $\beta$-glucans were further chromatographed on a DEAE-cellulose column. Fractions $(2 \mathrm{ml})$ were collected, and portions were counted for radioactivity. Results are expressed as total c.p.m. per column fraction and have been normalized to the original $5 \mathrm{ml}$ culture volume. DEAE-cellulose profiles are shown for ${ }^{14} \mathrm{C}$-labelled cyclic $(1,2)-\beta$ glucans extracted from 1021 cells (a) immediately after pulse-

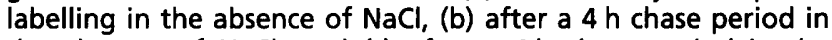
the absence of $\mathrm{NaCl}$, and (c) after a $4 \mathrm{~h}$ chase period in the presence of $0.4 \mathrm{M} \mathrm{NaCl}$. I-VI represent anionic cyclic $(1,2)-\beta$ glucan subfractions with increasing negative charge. $N$, neutral cyclic $(1,2)-\beta$-glucans.

$\left[{ }^{3} \mathrm{H}\right]$ phosphoglycerol-substituted cyclic $\beta$-glucans was reduced by $45 \%$ after 30 min into the chase period (Fig. 1). Whether this reduction resulted strictly from an inhibition of glucan backbone biosynthesis was further examined by performing pulse-chase experiments with $\left[{ }^{14} \mathrm{C}\right]$ glucose.

When cells were pulse-labelled with $\left[{ }^{14} \mathrm{C}\right]$ glucose, both neutral and anionic cyclic $(1,2)-\beta$-glucan fractions became radiolabelled (Fig. 2a). This result is similar to that previously reported by Geiger $e t$ al. (1991), although these researchers reported higher relative amounts of neutral cyclic $(1,2)-\beta$-glucans (e.g. $30 \%$ versus $10 \%$ for the experiments reported here). As expected, the total pool of ${ }^{14} \mathrm{C}$-labelled cyclic $\beta$-glucans did not increase during chase conditions in standard medium (Fig. 2b). There was, however, a progressive conversion of the neutral and less anionic forms of the cyclic $(1,2)-\beta$-glucans to the more highly anionic forms during the chase period (Fig. 2b). Specifically, the average negative charge of the total cyclic $(1,2)-\beta$-glucan pool increased from approximately 2 to 4 during the $4 \mathrm{~h}$ chase period (assuming that the anionic glucan subfractions contain 1 [subfraction I] to 6 [subfraction VI] negatively charged groups). These results are similar to those described by Geiger et al. (1991), who concluded that the neutral cyclic $(1,2)-\beta$-glucans are the biosynthetic precursors of the anionic cyclic $(1,2)-\beta$ glucans. That the ${ }^{14} \mathrm{C}$-labelled anionic cyclic $\beta$-glucans are, indeed, highly modified with phosphoglycerol substituents is indicated by the resistance of these molecules to mild alkali treatment (Geiger et al., 1991). Furthermore, double labelling experiments with $\left[{ }^{14} \mathrm{C}\right]$ glucose and $\left[{ }^{3} \mathrm{H}\right]$ glycerol revealed that the elution volumes for the ${ }^{14} \mathrm{C}$ and ${ }^{3} \mathrm{H}$-labelled anionic cyclic $(1,2)-\beta$-glucan subfractions I-VI were indistinguishable (data not shown).

In parallel experiments, cultures were subjected to a hyperosmotic shift with $0.4 \mathrm{M} \mathrm{NaCl}$ at the start of the chase period. Under these conditions, the conversion of neutral into anionic glucans was inhibited by more than $40 \%$ as compared to the control (Fig. $2 \mathrm{c}$ vs $2 \mathrm{~b}$ ). Furthermore, during these chase conditions, the average negative charge of the total cyclic $(1,2)-\beta$-glucan pool increased only to approximately 3 (vs 4 under isoosmotic chase conditions; see above). Similar results were obtained when $0.8 \mathrm{M}$ sucrose was used to hyperosmotically shock cell cultures (data not shown). Thus, these experiments clearly demonstrate that the transfer of phosphoglycerol substituents to the cyclic $(1,2)-\beta$-glucans is inhibited when cells are subjected to a hyperosmotic shift. This is in contrast to what is found during MDO biosynthesis in E. coli, where phosphoglycerol transferase I (the enzyme which mediates the transfer of phosphoglycerol head groups from phosphatidylglycerol to the MDO) has been shown to be fully active when cells are grown in media of high osmolarity (Bohin \& Kennedy, 1984).

\section{Synthesis of glycerophosphorylated cyclic $(1,2)-\beta$ - glucans is stimulated upon an osmotic downshift}

$R$. meliloti produces little, if any, cyclic $(1,2)-\beta$-glucans when growing in media containing high $\mathrm{NaCl}$ concentrations (Breedveld et al., 1990; Dylan et al., 1990). As expected, we were unable to detect the presence of glycerophosphorylated cyclic $(1,2)-\beta$-glucans in cultures of strain 1021 grown, pulse-labelled and chased in standard medium containing $0.4 \mathrm{M} \mathrm{NaCl}$. However, when these cultures were subjected to a hypoosmotic downshock during chase conditions, $\left[{ }^{3} \mathrm{H}\right]$ glycerophosphorylated cyclic $(1,2)-\beta$-glucans were detected within $30 \mathrm{~min}$ 


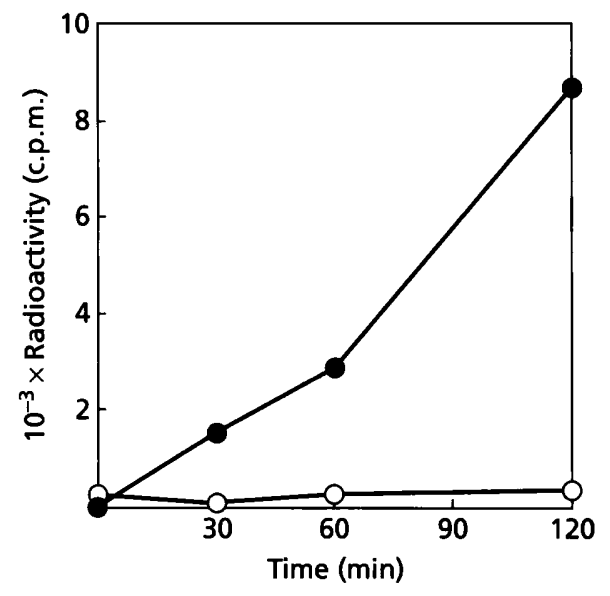

Fig. 3. Pulse-chase experiment with $\left[2-^{3} \mathrm{H}\right]$ glycerol. Cells of $\boldsymbol{R}$. meliloti 1021 were pulse-labelled with $\left[2-{ }^{3} \mathrm{H}\right]$ glycerol for $30 \mathrm{~min}$ in standard medium containing $0.4 \mathrm{M} \mathrm{NaCl}$. Chase conditions (beginning at time 0 ) were performed in the presence (O) or absence (O) of $0.4 \mathrm{M} \mathrm{NaCl}$. See the legend to Fig. 1 for additional details.

(Fig. 3). Furthermore, the rate of synthesis was similar to that measured in cells grown in standard medium containing no added $\mathrm{NaCl}$ (see Fig. 1).

The rapid appearance of radiolabelled glucans during hypoosmotic chase conditions indicates that all of the enzymes required for glycerophosphorylated cyclic $\beta$ glucan biosynthesis are present (but not active) within cells growing at high osmolarity. Additional experiments were performed in the presence of chloramphenicol in order to further examine this possibility. When cells grown in medium containing $0.4 \mathrm{M} \mathrm{NaCl}$ were subjected to a hypoosmotic shock in the presence of chloramphenicol $\left(100 \mu \mathrm{g} \mathrm{ml}^{-1}\right),\left[{ }^{3} \mathrm{H}\right]$ glycerophosphorylated cyclic $\beta$-glucans were synthesized at a rate approximately $55 \%$ that found for cells shocked in the absence of chloramphenicol. Further examination of the $\left[{ }^{3} \mathrm{H}\right]$ glycerophosphorylated $\beta$-glucans synthesized under both of these conditions using DEAE-cellulose column chromatography revealed profiles similar to those found for glucan preparations isolated from cells grown in media of low osmolarity (e.g. see Fig. 2a). Thus, it may be concluded that the enzymes required for cyclic $\beta$-glucan backbone biosynthesis as well as phosphoglycerol substituent addition are present within cells growing at high osmolarity. The activities of these enzymes, however, are inhibited under these growth conditions.

\section{Phosphoglycerol addition to the cyclic $(1,2)-\beta$-glucans occurs in the periplasm}

Although the cyclic (1,2)- $\beta$-glucans share many properties with the MDO of E. coli, one distinguishing feature is that essentially only anionic forms of the MDO are detected within the periplasmic compartment (Schulman, 1976; Kennedy, 1987). In fact, it has been proposed that the addition of a substituent to the MDO backbone serves as the signal for the release of these molecules to the periplasmic compartment (Goldberg et al., 1981). In contrast, neutral cyclic $(1,2)-\beta$-glucans are readily detected within the periplasmic compartment of R. meliloti (Miller et al., 1988; Breedveld et al., 1990; Zevenhuizen et al., 1990; Geiger et al., 1991). Whether the neutral, soluble, periplasmic forms of the cyclic $(1,2)-\beta$-glucans act as the biosynthetic precursors of the anionic cyclic $(1,2)-\beta$ glucans, however, remains unclear. In order to examine this possibility, the subcellular location of the neutral cyclic (1,2)- $\beta$-glucan biosynthetic precursors was determined using polymyxin $\mathrm{B}$ treatment after pulse-labelling cultures with $\left[{ }^{14} \mathrm{C}\right]$ glucose. The treatment of cultures with polymyxin B released $65 \%$ of the total (neutral and anionic) cyclic $(1,2)-\beta$-glucan fraction from cells after pulse-labelling. Because we have shown that essentially all of the neutral ${ }^{14} \mathrm{C}$-labelled cyclic $(1,2)-\beta$-glucans are converted to anionic forms during chase conditions (Fig. $2 \mathrm{a}, \mathrm{b})$, it may be concluded that the soluble, periplasmic form of the neutral cyclic $(1,2)-\beta$-glucans is, indeed, the biosynthetic precursor of the anionic cyclic $(1,2)-\beta$ glucans.

Control experiments performed with $\mathrm{R}$. meliloti LI1 (a $n d v A$ mutant) revealed that only $18 \%$ of the total cyclic $(1,2)-\beta$-glucans could be released by polymyxin B treatment. This is consistent with the results of previous studies which suggest a cytoplasmic location for the cyclic $\beta$-glucans of $n d v A$ mutants of $\mathrm{R}$. meliloti (Breedveld \& Miller, 1994). We have recently shown that strain LI1 synthesizes only neutral cyclic $(1,2)-\beta$-glucans, a result which provides further evidence that the addition of phosphoglycerol substituents to the cyclic $(1,2)-\beta$-glucan backbone occurs in the periplasmic compartment (Breedveld et al., 1994).

\section{DISCUSSION}

Despite the fact that the cyclic $(1,2)-\beta$-glucans of $R$. meliloti and the MDO of E. coli both become highly substituted with $s n$-1-phosphoglycerol moieties derived from the head group of phosphatidylglycerol, we have shown here that there are notable differences between the phosphoglycerol transferases of the two organisms. First, although the rhizobial enzyme(s) is constitutively synthesized, its activity is inhibited when cells are subjected to hyperosmotic stress. In contrast, the phosphoglycerol transferase I of E. coli retains full activity when cells are cultured at high osmolarity (Bohin \& Kennedy, 1984). Second, we have shown that neutral, soluble forms of the cyclic $(1,2)-\beta$-glucans within the periplasmic compartment are substrates for phosphoglycerol transfer. In contrast, soluble forms of the MDO have been shown to be poor substrates for the transfer of phosphoglycerol substituents from phosphatidylglycerol (Jackson et al., 1984). Furthermore, only traces of neutral soluble forms of the $\mathrm{MDO}$ are found in E. coli (Kennedy, 1987). Finally, we note that simple disaccharides (e.g. gentiobiose, sophorose) and $\beta$-glucosides (e.g. arbutin) have been shown to act as competitive substrates for both phosphoglycerol transferase I and II of E. coli (Bohin \& Kennedy, 1984; Goldberg et al., 1981; Jackson et al., 1984). While these substrates have proven to be extremely useful for in vivo 
and in vitro studies of these enzymic activities, repeated attempts using arbutin and sophorose as possible substrates for the rhizobial phosphoglycerol transferase(s) (both in vivo and in vitro) have been unsuccessful (M. Breedveld, unpublished results).

It is interesting that the enzymes associated with cyclic $\beta$ glucan biosynthesis in R. meliloti and MDO biosynthesis in E. coli appear to be synthesized constitutively. With the apparent exception of the phosphoglycerol transferase I of $E$. coli, the activity of these enzymes is reduced when cells are shifted to high-osmolarity environments (Bohin \& Kennedy, 1984; Kennedy \& Rumley, 1988; Rumley et al., 1992). When the effects of osmotic strength on the in vitro synthesis of MDO and cyclic $\beta$-glucan backbones were studied, it was revealed that backbone biosynthesis is dramatically inhibited by ionic solutes; however, nonionic solutes are not inhibitory (Zorreguieta et al., 1990; Rumley et al., 1992). Thus, the hyperosmotic downregulation of cyclic $(1,2)-\beta$-glucan and MDO backbone biosynthesis within growing cells is suggested to result from an increase in intracellular ionic strength (Zorreguieta et al., 1990; Rumley et al., 1992). In the present study, we show that the phosphoglycerol transferase activity of $R$. meliloti is inhibited by both ionic and nonionic solutes. Because the rhizobial phosphoglycerol transferase(s) is likely to be associated with the inner membrane (e.g. with its active site oriented towards the periplasmic compartment as shown for phosphoglycerol transferase I of E. coli: Bohin \& Kennedy, 1984) or soluble within the periplasmic compartment (e.g. as shown for phosphoglycerol transferase II of E. coli: Goldberg et al., 1981), intracellular ionic strength may not influence its activity. Alternatively, a loss of inner membrane turgor pressure or an increase in the osmotic strength within the periplasmic compartment may represent the environmental signals which down-regulate the activity of this enzyme(s).

Cyclic $(1,2)-\beta$-glucans of $R$. meliloti and $A$. tumefaciens have been found to function during hypoosmotic adaptation (Cangelosi et al., 1990; Dylan et al., 1990). In previous studies, the synthesis of both neutral and glycerophosphorylated cyclic (1,2)- $\beta$-glucans in R. meliloti and $A$. tumefaciens was repressed when cells were cultured in media of high osmotic strength (Miller et al., 1986; Breedveld et al., 1990; Zorreguieta et al., 1990). The present study confirms and extends these observations by showing that the transfer of phosphoglycerol moieties to the cyclic $(1,2)-\beta$-glucans in $R$. melilot $i$ is inhibited upon an osmotic upshift. Furthermore, our experiments reveal that the synthesis of glycerophosphorylated cyclic $(1,2)-\beta$ glucans is stimulated immediately upon an osmotic downshift. It is, therefore, likely that the anionic character of these molecules is important for their function(s) during hypoosmotic adaptation.

\section{ACKNOWLEDGEMENTS}

This research was supported by National Science Foundation grant DCB-9103924.

\section{REFERENCES}

Batley, M., Redmond, J. W., Djordjevic, S. P. \& Rolfe, B. G. (1987). Characterization of glycerophosphorylated cyclic $\beta$ - $(1,2)$-glucans from a fast-growing Rhizobium species. Biochim Biophys Acta 901, 119-126.

Bohin, J.-P. \& Kennedy, E. P. (1984). Regulation of the synthesis of membrane-derived oligosaccharides in Escherichia coli. Assay of phosphoglycerol transferase I in vivo. J Biol Chem 259, 8388-8393.

Botsford, J. L. \& Lewis, T. A. (1990). Osmoregulation in Rbizobium meliloti - production of glutamic acid in response to osmotic stress. Appl Environ Microbiol 56, 488-494.

Breedveld, M. W. \& Miller, K. J. (1994). Cyclic $\beta$-glucans of members of the family Rhizobiaceae. Microbiol Rev 58, 145-161.

Breedveld, M. W., Zevenhuizen, L.P. T. M. \& Zehnder, A. J. B. (1990). Osmotically-induced oligo- and polysaccharide synthesis by Rbizobium meliloti SU-47. J Gen Microbiol 136, 2511-2519.

Breedveld, M. W., Dijkema, C., Zevenhuizen, L.P. T. M. \& Zehnder, A. J. B. (1993). Response of intracellular carbohydrates to a $\mathrm{NaCl}$ shock in Rbizobium leguminosarum biovar trifolii $\mathrm{TA}-1$ and Rhizobium meliloti SU-47. J Gen Microbiol 139, 3157-3163.

Breedveld, M. W., Yoo, J. S., Reinhold, V. N. \& Miller, K. J. (1994). Synthesis of glycerophosphorylated cyclic $\beta$ - $(1,2)$-glucans by Rbizobium meliloti ndv mutants. J Bacteriol 176, 1047-1051.

Cangelosi, G. A., Martinetti, G. \& Nester, E. W. (1990). Osmosensitivity phenotypes of Agrobacterium tumefaciens mutants that lack periplasmic $\beta$-1,2-glucan. $J$ Bacteriol 172, 2172-2174.

Csonka, L. N. \& Hanson, A. D. (1991). Prokaryotic osmoregulation - genetics and physiology. Annu Rev Microbiol 45, 569-606.

Dylan, T., Helinski, D. R. \& Ditta, G. S. (1990). Hypoosmotic adaptation in Rbizobium meliloti requires $\beta$-(1,2)-glucan. $J$ Bacteriol 172, 1400-1408.

Geiger, O., Weissborn, A. C. \& Kennedy, E. P. (1991). Biosynthesis and excretion of cyclic glucans by Rbizobium meliloti 1021.J Bacteriol 173, 3021-3024.

Goldberg, D. E., Rumley, M. K. \& Kennedy, E. P. (1981). Biosynthesis of membrane-derived oligosaccharides: a periplasmic phosphoglyceroltransferase. Proc Natl Acad Sci USA 78, 5513-5517.

Hirst, T. R. \& Holmgren, J. (1987). Transient entry of enterotoxin subunits into the periplasm occurs during their secretion from Vibrio cholerae. J Bacteriol 169, 1037-1045.

Jackson, B. J. \& Kennedy (1983). The biosynthesis of membranederived oligosaccharides. A membrane-bound phosphoglycerol transferase. J Biol Chem 258, 2394-2398.

Jackson, B. J., Bohin, J.-P. \& Kennedy, E. P. (1984). Biosynthesis of membrane-derived oligosaccharides: characterization of $m d o B$ mutants defective in phosphoglycerol transferase I activity. $J$ Bacteriol 160, 976-981.

Kennedy, E. P. (1987). Membrane-derived oligosaccharides. In Escherichia coli and Salmonella typhimurium: Cellular and Molecular Biology, vol. 1, pp. 672-679. Edited by F. C. Neidhardt, J. L. Ingraham, K. B. Low, B. Magasanik, M. Schaechter \& H. E. Umbarger. Washington, DC: American Society for Microbiology.

Kennedy, E. P. \& Rumley, M. K. (1988). Osmotic regulation of biosynthesis of membrane-derived oligosaccharides in Escherichia coli. J Bacteriol 170, 2457-2461.

Miller, K. J., Kennedy, E. P. \& Reinhold, V. N. (1986). Osmotic adaptation by gram-negative bacteria : possible role for periplasmic oligosaccharides. Science 231, 48-51.

Miller, K. J., Reinhold, V. N., Weissborn, A. C. \& Kennedy, E. P. 
(1987). Cyclic glucans produced by Agrobacterium tumefaciens are substituted with $s n$-1-phosphoglycerol residues. Biochim Biophys Acta 901, 112-118.

Miller, K. J., Gore, R. S. \& Benesi, A. J. (1988). Phosphoglycerol substituents present on the cyclic $\beta$-1,2-glucans of Rbizobium meliloti 1021 are derived from phosphatidylglycerol. J Bacteriol 170, 4569-4575.

Rumley, M. K., Therisod, H., Weissborn, A. C. \& Kennedy, E. P. (1992). Mechanisms of regulation of the biosynthesis of membranederived oligosaccharides in Escherichia coli. J Biol Chem 267, 11806-11810.

Schulman, H. (1976). Biosynthesis of the membrane-derived oligosaccharides of Escherichia coli. PhD Dissertation, Harvard University.

Schulman, H. \& Kennedy, E. P. (1977). Relation of turnover of membrane phospholipids to synthesis of membrane-derived oligosaccharides of Eschericbia coli. J Biol Chem 252, 6299-6303.

Smith, L. T. \& Smith, G. M. (1989). An osmoregulated dipeptide in stressed Rbizobium meliloti. J Bacteriol 171, 4714-4717.

Zevenhuizen, L. P. T. M., Van Veldhuizen, A. \& Fokkens, R. H. (1990). Re-examination of cellular $\beta$-1,2-glucans of Rbizobiaceae: distribution of ring sizes and degrees of glycerol-1-phosphate substitution. Antonie Leeuwenboek 57, 173-178.

Zorreguieta, A., Cavaignac, S., Geremia, R. A. \& Ugalde, R. A. (1990). Osmotic regulation of $\beta(1,2)$ glucan synthesis in members of the family Rhizobiaceae. J Bacteriol 172, 4701-4704.

Received 21 June 1994; revised 24 October 1994; accepted 31 October 1994. 